\title{
Research about the Removal Effect of the Constructed Wetland System on the Escherichia Coli K12
}

\author{
Lieyu Zhang ${ }^{1}$, Yu-Bing Ye ${ }^{1,2}$, Beidou Xi ${ }^{1}$, Lei Wang ${ }^{1}$, Tian Liu ${ }^{1,2}$, Pengfei $\mathrm{Yu}^{1,3}$, Jingjing $\mathrm{Lv}^{1,4}$. \\ ${ }^{1}$ Laboratory of Water Environmental System Engineering, Chinese Research Academy of Environmental Science, Beijing \\ 100012, China, \\ ${ }^{2}$ School of Resources and Environmental Engineering, Wuhan University of Technology, Hubei, Wuhan 430070, China, \\ ${ }^{3}$ School of Resources and Environmental Science, Wuhan University, Hubei, Wuhan 430070, China, \\ ${ }^{4}$ College of Environmental Science and Engineering, Tongji University, Shanghai 200092, China.
}

\begin{abstract}
This paper analyzed the related methodsto removethe biological indicatorEscherichia coli $\mathrm{K} 12$ (E. coli $\mathrm{K12}$ ) in the constructed wetland system (CWs), which included filtration and absorption of filling, effect of the plant root system and microorganism phagocytosis and so on. It indicated that $\mathrm{E}$. coli $\mathrm{K} 12$ was mainly removed through filtration and absorption of filling, about $80 \%$ was removed by this process. Plants and microorganisms alsocontributed to the removal of $\mathrm{E}$. coli $\mathrm{K12}$. The removal load of $\mathrm{E}$. coli $\mathrm{K} 12$ increased with the addition ofpollution load. When hydraulic retention time (HRT) was $4 \mathrm{~d}$, there was a better linear relation $\left(R^{2}=0.9998\right)$ between the removal load of $E$. coli K12 and pollution load. Meanwhile, it had a close relation between inactivation ratio of $\mathrm{E}$. coli $\mathrm{K12}$ and hydraulic load, the lower hydraulic load was, the higher inactivation ratio was.
\end{abstract}

Keywords-constructed wetland system (CWs); escherichiacoli; Inactivation ratio; HRT; Pollution load.

\section{INTRODUCTION}

The pathogenic bacteria in sewage have seriously threatened public health, it is one of the most serious public health problems against human's progress[1, 2]. People have paid close attention to the method about how to detect and sterilize the pathogenic bacteria in domestic wastewater effectively. E. coli is regarded as the most sensitive indicatorof fecal contamination inthe natural environment of water, soils and plants[3, 4, 5]. It has been the indicator bacteria for the Chinese drinking water standard all the time. At present, chlorine, chlorine dioxide, ozone, ultraviolet ray etc. are common methods for water sterilization. Recently, the constructed wetland system (CWs) has drawn great attention because of its prominent advantages, such as robust, lowexternal energy requirements, easy to operate andmaintain[6, 7].It has been reported that in some CWs, the removal rate of $\mathrm{E}$. coli and streptococcus caesium reached $90 \%$ and more than $80 \%$, respectively[8]. Song's[9] research indicated that the CWs could effectively remove 99.9\% Escherichia coli. Other researches also showed that the CWs had good performance in the removal of pathogenic bacteria [10,11].However, most of them only studied single factor.

The studycomprehensive studied effect of the fillings, hydraulic load, hydraulic retention time (HRT), microorganism and plant etc. on the removal ofE. coli K12, explored the optimaldesign parameters for the CWs to remove the pathogenic bacteria. Meanwhile, it initially studied the methods about removal of the pathogenic bacteria in the CWs, provided computing technique and design consideration for the large-scale management of rural domestic wastewater.

\section{MATERIAL AND METHOD}

\section{A. Experimental facility}

Four groups of testing apparatuses were used to simulate horizontal plug flow subsurface constructed wetland. The sewage flowed into the bed body from one side, then flowed through the filling bed horizontally after homogeneous water distribution, and outflowed from the bottom of the system. The whole cell body was made of plastic to avoid infiltration. Each wetland cell was $0.9 \mathrm{~m} \times$ $0.5 \mathrm{~m} \times 0.5 \mathrm{~m}$, the bottom gradient was $1 \%$. The system was divided into suction stage, processing stage, discharge stage.

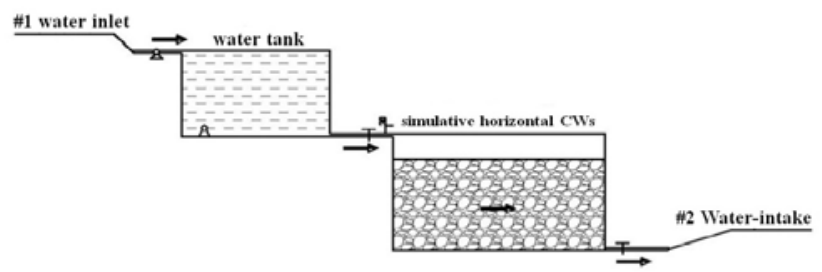

Figure 1. Diagrammatic sketch of experimental device

The water inlet of the testing apparatus was set at $0.1 \mathrm{~m}$ over the system, the sewage was sent into the system from the inlet pipe. Globe valve was used to regulate water content for each testing apparatus. Overflow weir was set in the end to distribute water homogeneously.

The processing area was $0.9 \mathrm{~m} \times 0.5 \mathrm{~m} \times 0.45 \mathrm{~m}$, and the bottom gradient was $1 \%$. The fillings were consist of two parts: the super stratum was a mix matrix of coarse sand and soil (2:1) with a thickness of $25 \mathrm{~cm}$, the bottom was gravel, whose grain size is around $20 \mathrm{~mm}$, with a thickness of $15 \mathrm{~cm}$. The two parts were separated by geotechnical cloth. The planting density was 10 plants per square meter. 
The water inlet was set at the bottom of the testing apparatus, $3 \mathrm{~cm}$ over the ground. To avoid blocking, the water inlet was parceled with gauze and gravel was paved.

\section{B. Experiment materials}

In order to accomplish the research successfully, the necessary materials were as following: medium sand, whose grain size is between 0.35 and $0.5 \mathrm{~mm}$; gravel; calamus and clinopodiumurticifolium. The sewage used in the experiment was artificially made up, and E. coli K12 was bought from Shanghai Industrial Microbiology Institute.

\section{Experimental contents}

The designed running time was six months, except for the debug time, which would not exceed 15d. The experiment has been divided into four groups, and the detailed design was listed in Table 1.

TABLE I. ANALOg DEVICE TYPE

\begin{tabular}{|c|c|c|c|}
\hline \multicolumn{2}{|c|}{ Group } & Fillings & Others \\
\hline \multicolumn{2}{|l|}{ W1 } & $\begin{array}{c}\text { medium sand, gravel, } \\
\text { soil }\end{array}$ & E. coli K12 \\
\hline \multirow{2}{*}{ 'W2 } & W21 & $\begin{array}{c}\text { medium sand, gravel, } \\
\text { soil }\end{array}$ & calamus,E. coli K12 \\
\hline & W22 & $\begin{array}{c}\text { medium sand, gravel, } \\
\text { soil }\end{array}$ & $\begin{array}{c}\text { clinopodiumurticifolium, } \\
\text { E. coli K12 }\end{array}$ \\
\hline \multicolumn{2}{|c|}{$\begin{array}{l}\text { Control } \\
\text { group }\end{array}$} & no filling & E. coli K12 \\
\hline
\end{tabular}

Firstly, in order to explore the influence of matrix filling, plant and activated sludge on the removal of pathogenic bacteria, we compared the control group with $\mathrm{W} 1$, W3 with $\mathrm{W} 1$, respectively. And then, at the condition of $28^{\circ} \mathrm{C}$ and $40 \mathrm{~cm}$ water depth, the removal effect and load in the CWs were studied when the HRT was 2, 3 and $4 \mathrm{~d}$ as well as the pollution load was $10^{3}, 10^{4}$ and $10^{5} \mathrm{cfu} / \mathrm{ml}$, respectively.

\section{Detection method}

Plate count was adopted to measure the E. coli K12 in the laboratory test. Microorganicinactivation ratio was used to evaluate the sterilizing effect in the CWs, the inactivation ratio was calculated as follows:

$$
\text { Inactivation ratio }=\frac{N_{0}-N}{N_{0}} \times 100 \%
$$

Where $\mathrm{N}_{0}$ was the number of microorganism in the influent water, $\mathrm{N}$ was the left number of microorganism in the same amount of water after the treatment of the CWs.

\section{RESUlT AND DISCUSSION}

\section{A. Removal effect of filling on the E. coli K12}

The results of natural inactivation of E. coli K12 and the filtration and absorption of the matrix fillings were shown in Fig.2.

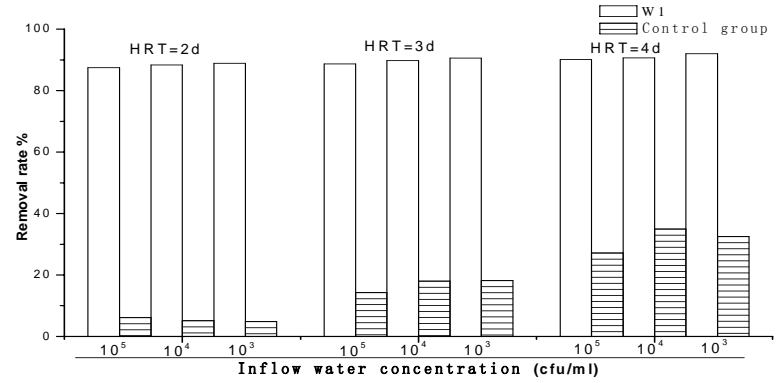

Figure 2. Removal rate of filtration and absorption of the matrix filling and natural inactivation of E. coli K12 under different HRT and inflow water concentration.

The result revealed that, the inactivation ratio of filling bed on the E. coli K12 increased with the increase of HRT when the influent water concentration ranged between $1 \times$ $10^{3}$ and $1 \times 10^{5} \mathrm{cfu} / \mathrm{ml}$. When the HRT was $2 \mathrm{~d}$, the maximum removal rate of natural inactivation of $\mathrm{E}$. coli K12 was only $6.2 \%$ in the control group, however, the minimum removal rate was $87.5 \%$ in group W1. So, the minimum removal rate of the filtration and absorption of the matrix fillings was $81.3 \%$. When the HRT was $3 \mathrm{~d}$ and $4 \mathrm{~d}$, the average removal rate of the filtration and absorption of the matrix fillings was $72.87 \%$ and $59.37 \%$, respectively, the average removal rate of natural inactivation of $\mathrm{E}$. coli K12 was $16.83 \%$ and $31.57 \%$, respectively.

It indicated that the filtration and absorption of the matrix fillingswas the main reason of the inactivation of $\mathrm{E}$. coli K12. Meanwhile, at the same HRT, with the increase of pollution load in influent water, natural inactivation accounted for more in the whole removal rateof E. coli K12, while the filtration and absorption of the matrix fillings accounted for less. At the same pollution load, with the increase of HRT, the removal rate of natural inactivation of E. coli increased, while the filtration and absorption of the matrix fillings decreased, which could be due to the desorption along the wetland bed.

\section{B. Removal effect of plant on the E. coli K12}

Group W1,W31 and W32 were used for this experiment.The initial concentration of E. coli K12 was controlled around $10^{4} \mathrm{cfu} / \mathrm{ml}$, and then added up to around $10^{5} \mathrm{cfu} / \mathrm{ml}$ half month later. The change of E. coli K12 in the CWs was shown in Fig.3. 

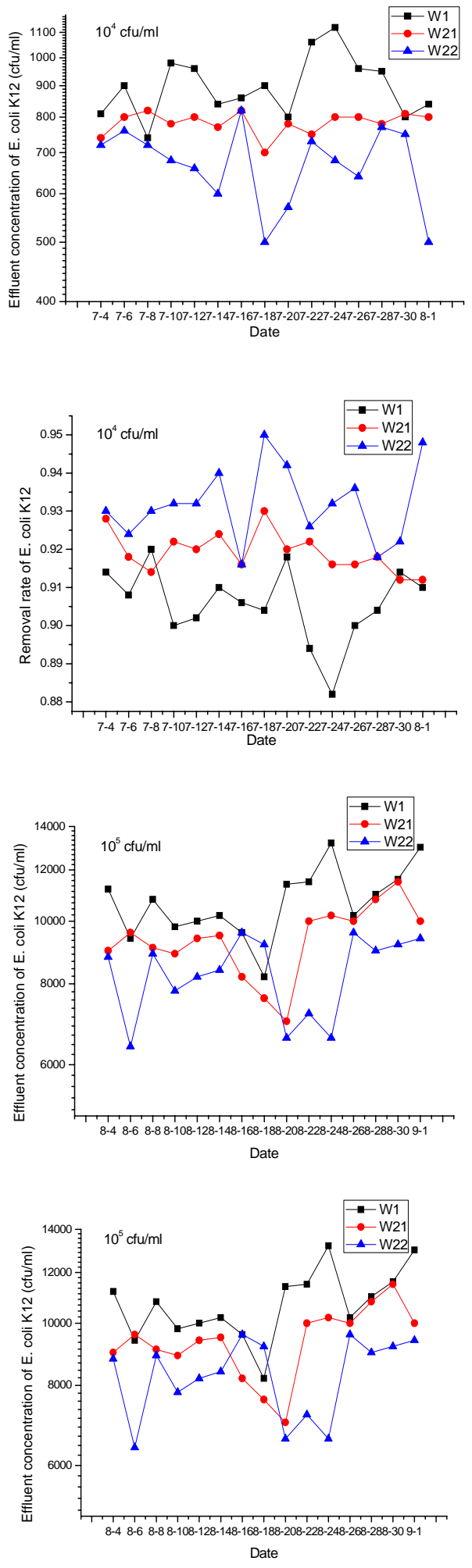

Figure 3. Removal effect of plant on the E. coli K12 under different initial concentrations of E. coli K12
As we could see in Fig.3, plant could help to promote the effluent quality of subsurface wetlandto a certain degree, and, calamusperformed better than clinopodiumurticifolium. Under different initial concentration of E. coli K12, the average inactivation ratio of calamus on E. coli K12 was 93.19\% and $91.60 \%$, and the clinopodiumurticifolium's was $91.92 \%$ and $90.35 \%$, while the W1's was only $90.57 \%$ and $88.92 \%$. That is because calamus has a more developed root, which could provide better Breeding habitats for microorganisms. However, the effluent quality of clinopodiumurticifolium was more stable.

\section{Removal effect of pollution load on the E. coli K12}

At the condition of $28^{\circ} \mathrm{C}$ and $40 \mathrm{~cm}$ water depth, the removal effect and load of E. coli K12 in the CWs were studied when the HRT was 2,3 and $4 \mathrm{~d}$ as well as the pollution load was $10^{3}, 10^{4}$ and $10^{5} \mathrm{cfu} / \mathrm{ml}$, respectively. The removal effect of E. coli K12in the CWs under different HRT and pollution load was shown in Fig.4.
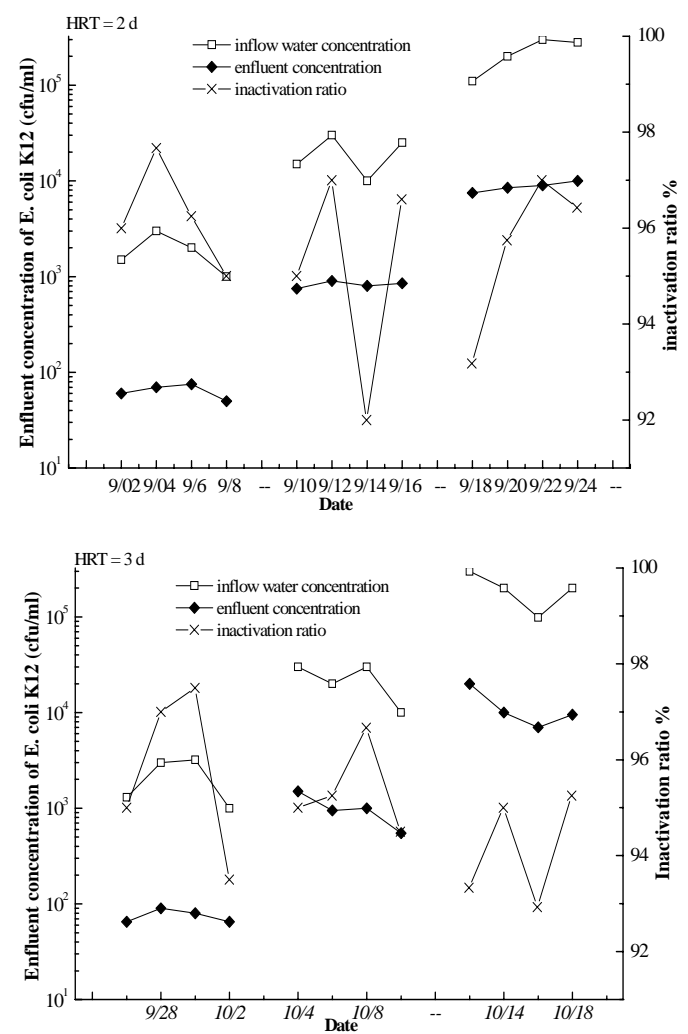

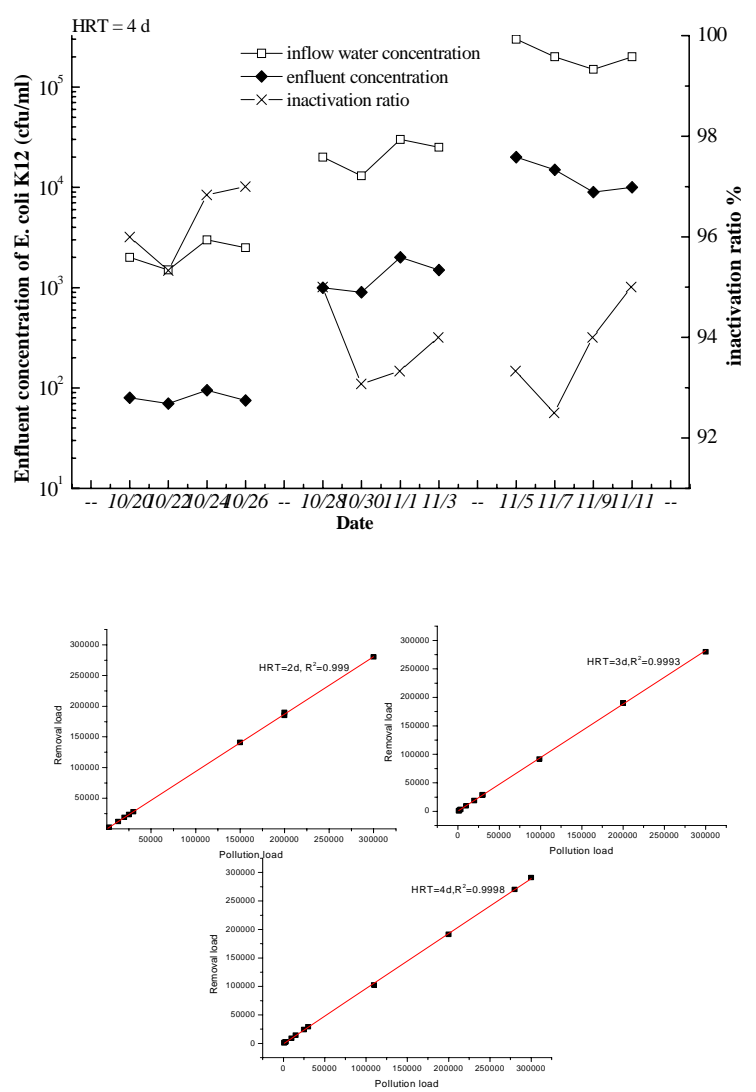

Figure 4. Removal effect of pollution load on the E. coli K12 under different HRT

As we could see in Fig.4, at the same HRT, with the increase of pollution load, the effluent concentration increased, the removal rate of E. coli K12 decreased. At the same pollution load, with the increase ofHRT,the effluent concentration decreased, and the removal rate of E. coli K12increased. Moreover, when HRT was 4d, there was a better linear relation $\left(\mathrm{R}^{2}=0.9998\right)$ between the removal load of $\mathrm{E}$. coli $\mathrm{K} 12$ and the inflow water load, and, with the increase of pollution load, it performed a corresponding better treatment effect.

\section{Removal effect of hydraulic loadon the E. coli K12}

At the condition of $28^{\circ} \mathrm{C}$ and $40 \mathrm{~cm}$ water depth, when the HRT was 3d, the removal effect of the CWs on the E. coli K12 under different hydraulic load was shown in Fig.6.

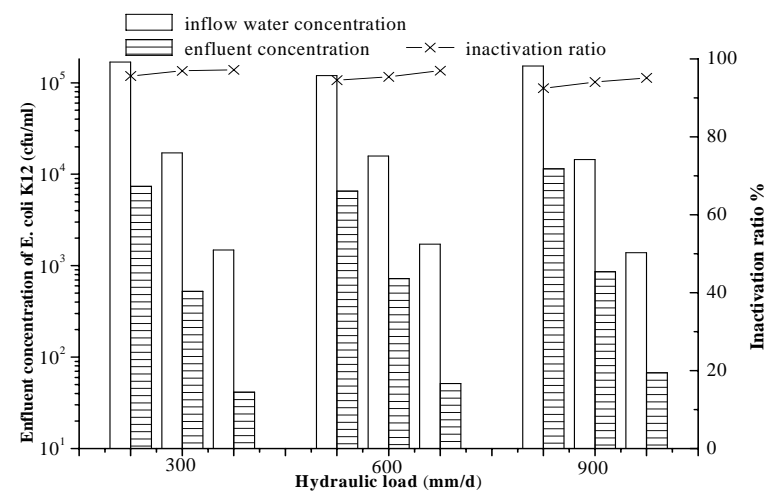

Figure 5. Removal effect of hydraulic load on the E. coli K12.

As we could see in Fig.5, the inactivation ratio of the CWs on the E. coli K12 had a close relation with hydraulic load. When the hydraulic load was 300, 600 and $900 \mathrm{~mm} / \mathrm{d}$, the average inactivation rate was $96.58 \%, 95.65 \%$ and $93.90 \%$, respectively. So, at the same pollution load, the higher the hydraulic load was, the worse the effluent quality. This is because that the higher hydraulic load would lead to shorter HRT, so the E. coli K12 would be brought out from the CWs before it could be adsorbed and filtrated, which would be bad for the purification of pollutant and reduce inactivation effect of pathogenic bacteria.

\section{CONCLUSION}

1.Filtration and absorption of the matrix fillingswas the main reason of the inactivation of E. coli K12.Meanwhile, at the same HRT, with the increase of pollution load in influent water, natural inactivation accounted for more in the whole removal rateof E. coli K12. At the same pollution load, with the increase of HRT, the removal rate of natural inactivation of E. coli increased, while the filtration and absorption of the matrix fillings decreased.

2.Plant could help to promote the effluent quality of subsurface wetlandto a certain degree, and calamusperformed better than clinopodiumurticifolium.

3. At the same HRT, the effluent concentration increased and the removal rate of $\mathrm{E}$. coli $\mathrm{K} 12$ decreasedwith the increase of pollution load. At the same pollution load,the effluent concentration decreased and the removal rate of $\mathrm{E}$. coli K12increased with the increase ofHRT. Moreover, when HRT was $4 \mathrm{~d}$, there was a better linear relation $\left(\mathrm{R}^{2}=\right.$ 0.9998) between the removal load of E. coli K12 and the inflow water load, and,it performed a corresponding better treatment effect with the increase of pollution load.

4.The inactivation ratio of the CWs on the E. coli K12 had a close relation with hydraulic load. At the same pollution load, the higher the hydraulic load was, the worse the effluent quality. When the hydraulic load was 300, 600 and $900 \mathrm{~mm} / \mathrm{d}$, the average inactivation rate was $96.58 \%$, $95.65 \%$ and $93.90 \%$, respectively. 


\section{V.CORRESPONDING AUTHOR}

Name: Lie-Yu Zhang

Tel: +86 01051095613

Fax: +86 01051095613

E-mail address: zhanglieyu@163.com

Address: 8DayangfangBeiYuan Road, Chaoyang District, Beijing 100012, China.

\section{ACKNOWLEDGEMENTS}

This study was financially supported by grant 51208485 from the Natural Science Foundation, 2012BAJ21B06 and 2012BAJ21B04 from the Key Projects in the National Science \& Technology Pillar Program, and 201109024 from the National Environmental Protection Public Welfare Science and Technology Research Program of China.

In addition, we thank the anonymous reviewers for their careful review of this manuscript and their valuable suggestions.

\section{REFERENCES}

[1] J.F. Schijven, H.H.J.L. van den Berg, M. Colin, Y. Dullemont, W.A.M. Hijnen, A. Magic-Knezev, W.A. Oorthuizen, G. Wubbels.A mathematical model for removal of human pathogenic viruse sand bacteria by slow sand filtration under variable operational conditions.Water Res, 47, 2592-2602, 2013.

[2] K.Y. Chan, W.W. Ye, Y. Zhang, L.D. Xiao, P.H.M. Leung, Y. Li, M. Yang, Ultrasensitive detection of E. coli O157:H7 with biofunctional magnetic bead concentration via nanoporous membrane based electrochemical immunosensor.Biosens.Bioelectron, 41, 532-537, 2013.

[3]Edberg, S.C.,Rice, E.W.,Karlin,R.J.,Allen,M.J. Escherichia coli:the best biological drinking water indicator for public health protection. Symp. Ser. Soc. Appl. Microbiol, 29, 106S-116S,2000.

[4] Haller, L., Pote, J., Loizeau, J-L., Wildi, W. Distribution and survival of fecalIndicator bacteria in the sediments of the Bay of Vidy, Lake Geneva, Switzerland. Ecol. Indic,9, 540-547, 2009.

[5] Stevens, M., Ashbolt, N., Cunliffe, D. Review of Coliforms as Microbial Indicators of Drinking Water Quality. Recommendations to Change the Use of Coliforms as Microbial Indicators of Drinking Water Quality.Australian Government National Health and Medical Research Council.Biotext Pty Ltd., Canberra, 2003.

[6] Brix, H. How 'green' are aquaculture, constructed wetlands and conventional wastewater treatment systems.Water Sci. Technol, 40 (3), 45-50, 1999.

[7] Vymazal, J. The use constructed wetlands with horizontal sub-surface flow for various types of wastewater. Ecol. Eng, 35, 1-17, 2009.

[8] Karathanasis AD PC, Coyne MS. Vegetation effects on fecal bacteria, BOD, and suspended solid removal in constructed wetlands treating domestic wastewater. Ecol. Eng,20(2), 157-69,2003.

[9] Song Z ZZ, Li J et al. Seasonal and annual performance of a full-scale constructed wetland system for sewage treatment in China. Ecol. Eng,26(3), 272-82, 2006.

[10] Karpiscak MM GC, Watt PM Multi-species plant systems for wastewater quality improvements and habitat enhancement. Water Sci. Technol, 33(10-11), 231-6,1996.

[11] Walshe GE PL, Flury M et al. Effects of pH, ionic strength, dissolved organic matter, and flow rate on the co-transport of MS2 bacteriophages with kaolinite in gravel aquifer media. Water Res, 2009. 